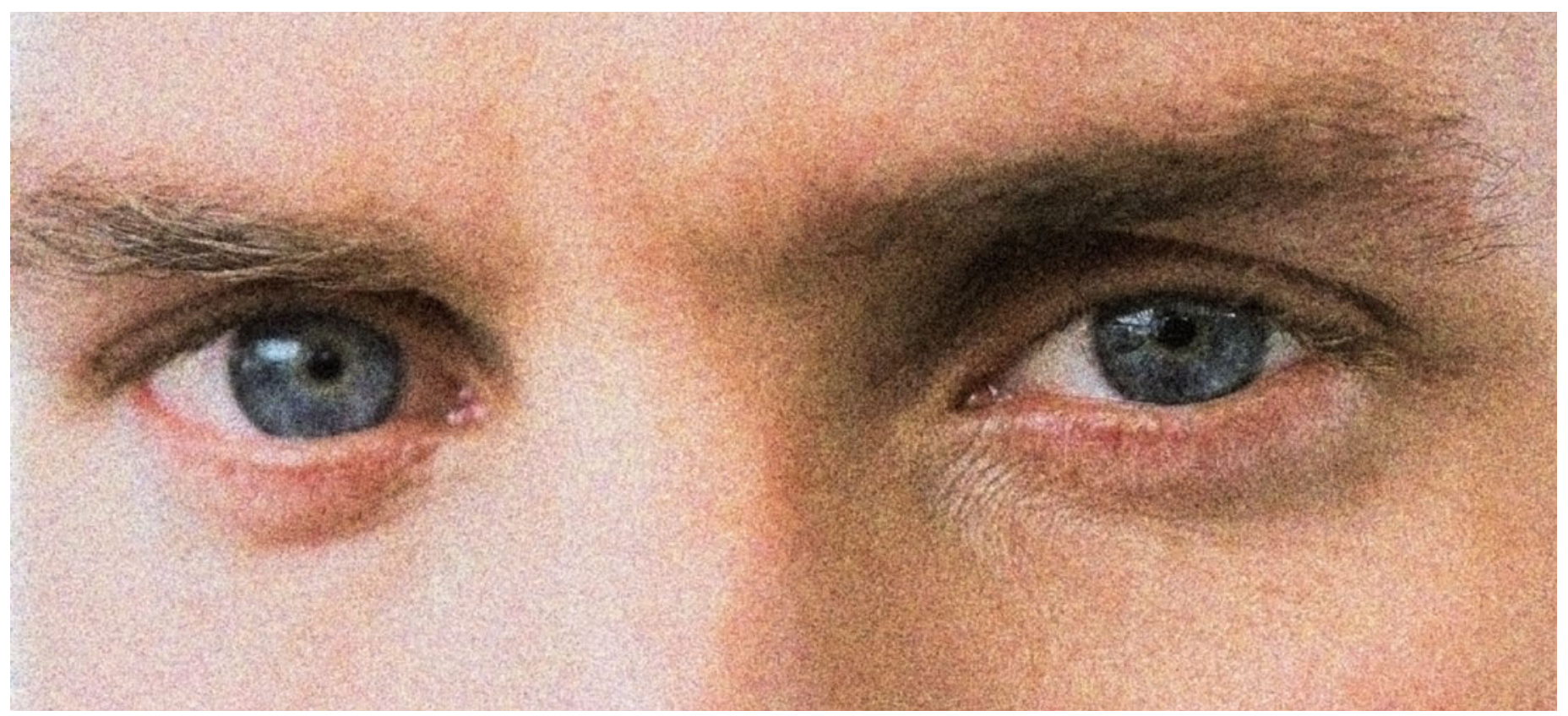

\title{
Blaue Augen
}

\section{Andreas Osterwalder}

Dr. med., Mitglied FMH

All die Jahre hat mich eine Geschichte, eine wahre Geschichte verfolgt, die sie mir vor einigen Jahren erzählt hatte. Es begann harmlos bei einem Cocktail in der luxuriösen Villa des wohlhabenden Ärztepaars. Mit einem Glas Champagner hat sie sich zu mir gesetzt. Sie mochte mich, seit ich sie an einem Knie operiert hatte, und gab mir immer einen Ehrenplatz bei ihren Einladungen. Die Gesellschaft entsprach nicht unbedingt meinem Geschmack, zu mondän, aber M. und ihr Mann waren mir sympathisch, abgesehen vom immer exquisiten Essen.

\section{Inmitten des wirren Geplauders der Cham- pagner schlürfenden Gäste wurde es plötzlich eiskalt, und ihr Gesicht war mit unendlicher Traurigkeit erfüllt.}

Sie setzte sich also zu mir und zündete eine Zigarette an; sie, eine schlanke, braungegerbte Frau von gut 70 Jahren (ich habe mich gefragt, ob sie regelmässig unter der Höhensonne lag, schrieb dann aber den dunklen Teint ihrer südländischen Abkunft zu). Die stark geprägten Gesichtszüge verliehen ihr ein fast hartes Aussehen, was aber durch das liebenswürdige Wesen Lüge gestraft wurde. Schwarzes Haar umrahmte das Gesicht, aus dem zwei dunkle Augen den lebhaften Charakter der Griechin verrieten. M. war immer guter Laune, sehr temperamentvoll und stellte einen scharfen Kontrast zu ihrem sanftmütigen, ruhigen Mann. Beim Anzünden der Zigarette - sie war eine starke Raucherin, was man an ihrer rauhen Stimme leicht erriet zitterten ihre Hände stark, eine Eigenart, an die wir uns alle gewöhnt hatten. Da das Zittern dieses Mal ausgeprägter als üblich war, erkannte sie meinen etwas erstaunten Blick. Sie schaute mich mit einem warmen Blick an und sagte:

«Weisst du, A., ich habe nicht immer gezittert. Das hat schlagartig mit 14 Jahren begonnen, und zwar im Zug von Athen nach Piräus.»

Inmitten des wirren Geplauders der Champagner schlürfenden Gäste wurde es plötzlich eiskalt, und ihr Gesicht war mit unendlicher Traurigkeit erfüllt. Mich schauderte.

«Mitten im Krieg war ich mit meiner Mutter in einem überfüllten Eisbahnwagen, um auf dem Land bei Verwandten Lebensmittel zu holen. Die Nazis mit ihrem 
strengen Regime hungerten die Bevölkerung systematisch aus. Es war ein heisser Sommertag. Die Luft im Zug war stickig. Es roch nach Schweiss, und die Leute drängten sich Körper an Körper. Wir hatten mit viel Glück einen Sitzplatz ergattert. Gegenüber von mir, dem 14-jährigen Mädchen, sass ein junger deutscher Offizier. Die sonst angeregt schwatzenden und gestikulierenden Passagiere blieben um ihn herum seltsam still und schauten mit gesenktem Blick auf irgendeinen imaginären Fixpunkt. Verstohlen suchte ich sein jungenhaftes Gesicht, das von der Hitze leicht gerötet mit Schweissperlen bedeckt war. Neben den streng gescheitelten und nach hinten gekämmten blonden Haaren fielen mir sofort seine blauen, himmelblauen Augen auf. Auch er schien gehemmt und suchte mit seinem Blick einen Ort, der seine Unsicherheit festhalten konnte. Er schien mir nicht so viel älter als ich, und, sofort beschämt, stellte ich ihn mir als meinen Freund und Geliebten vor. Da hatte er mein Interesse bemerkt und warf mir einen schnellen, ja, gehetzten Blick zu, als der Zug mit einem heftigen Ruck zum Stillstand kam.

\section{Das Erstaunen wich immer mehr einer Zornes- röte, er hatte im wahren Sinn des Wortes sein Gesicht verloren.}

Es kam Bewegung in die Menge, und Fahrgäste stiegen aus und ein. Hinter «meinem» Offizier erschien eine hochschwangere Frau, nicht viel älter als zwanzig, die sich, ihren Bauch mit beiden Händen haltend, an seine Bank lehnte. Meinem Blick folgend drehte er sich um und sprang abrupt (zackig wäre hier das passendere Wort) auf. In soldatischer Manier bot er seinen Platz der Schwangeren an. Beide schienen mir überrascht, der Offizier fast gedemütigt von seinem unbeherrschten Reflex. Der leise Ausdruck der Scham wich sofort einem Ausdruck der Überraschung, als ihn die Frau verlegen, aber bestimmt mit beiden Händen abwies. Alle Fahrgäste in der Umgebung waren verstummt und schauten mit offenen Mündern auf die zwei. Der Offizier, plötzlich im Mittelpunkt eines ihm offensichtlich unangenehmen Interesses, setzte sich wieder mit errötetem Gesicht. Das Erstaunen wich immer mehr einer Zornesröte, er hatte im wahren Sinn des Wortes sein Gesicht verloren. Der Blick, starr, aber flackernd, durchbohrte immer noch die Rücklehne über meinem Kopf. Nur die jetzt vermehrt spriessenden Schweissperlen liessen die immer noch stumme Menge ahnen, was hinter dieser Stirne vor sich ging. Kein Laut unterbrach das monotone Rumpeln des Zuges; unterdessen hatten auch die weiter weg Sitzenden erahnt, dass sich etwas Unheilvolles zugetragen hatte. Der Ruck des bremsenden Zuges schien die Erlösung zu bringen, und die erstarrte Menge erwachte.

Mit einer plötzlichen Geste, wie wenn er etwas vergessen hätte, öffnete der Offizier den Pistolenhalfter und zog die Waffe.

Als der letzte Aussteiger den Waggon verlassen hatte, sprang der Offizier plötzlich auf, packte die Frau grob am Oberarm und zwang sie durch den Zugskorridor zum Ausgang. Gebannt folgten wir dem Geschehen und, einmal ausser Sicht, drängten wir ans Fenster. Stolpernd, immer noch im Griff des Offiziers, taumelte die Gestossene auf das Perron. Einen kurzen Moment standen beide regungslos. Mit einer plötzlichen Geste, wie wenn er etwas vergessen hätte, öffnete der Offizier den Pistolenhalfter und zog die Waffe. Seitwärts blickend, ein ungläubiges Erstaunen in den Augen, sah die Frau, wie der Pistolenlauf an ihre Schläfe geführt wurde. Mein Blick war auf den Offizier gerichtet, der immer noch starr, jetzt ohne zu flackern, vorausschaute und dann abdrückte. Das Hirn spritzte in einer Blutfontäne aus der Gegenseite des Kopfes, und die Frau sackte lautlos auf die Plattform. Ein unterdrückter Aufschrei von uns und leises unterdrücktes Wimmern im Waggon! Wie lange ich am Fenster stand, weiss ich nicht mehr. Als ich mich zum Sitz zurücktastete, sass der Offizier schon auf seinem Platz. Er schaute wieder regungslos und steif über meinen Kopf. Meine Hände zitterten. Jetzt schaute ich in seine Augen - in seine stahlblauen Augen!»

Bildnachweis

(c) Wavebreakmedia Ltd | Dreamstime.com; modifiziert durch EMH 